\title{
Mağazadan Satın Alma Davranışında Dokunma İhtiyacının Rolü
}

\author{
The Role of Need for Touch in Store Shopping \\ Zeynep Sevgi Ballk ${ }^{* 1}$ \\ ${ }^{1}$ Department of Business Administration, Sirnak University, Sirnak, Turkey
}

\begin{abstract}
Received: 19.06 .2021
Accepted: 30.07 .2021

This article was checked by intihal.net

\section{Öz}

Beş duyudan biri olan dokunma duyusu bireyler tarafından ürün satın alım öncesi bir değerlendirme aracı olarak kullanılmaktadır. Tüketicilerin mağazadan satın almada karşılaşacaklarını düşündükleri fiyat dezavantajı online alışverişe yönlenmelerine neden olmakla birlikte, dokunma ihtiyacına sahip olmaları da mağazadan alışverişe yöneltmektedir. Bunun yanında mağazadan satın almak için harcayacakları çaba da mağazadan satın alma niyetini etkilemektedir. Ancak mağaza içinde fiyat karşılaştırması yapabilme kolaylığı, risk faktörüne ilişkin algılarını etkileyebileceğinden satın alma niyetleri de pozitif yönde etkilenebilmektedir. Çalışmada bireylerin dokunma ihtiyacını ve bu bağlamda mağazadan alışveriş eğilimlerinin ne doğrultuda olduğunu inceleme konusu yapmışlardır. Katılımcılardan yeni bir cep telefonu satın aldıklarını düşünmeleri istenmiş ve sonrasında araştırma soruları yöneltilmiştir. Araştırma sonucunda kadın ve erkekler arasında dokunma ihtiyacı düzeyi bakımından bir farklılık gözlemlenmemekle birlikte, dokunma ihtiyacı arttıkça mağazadan satın alma davranışının da arttığı gözlemlenmiştir. Ayrıca algılanan çaba ve algılanan risk arttıkça, mağazadan satın alıma niyeti azalış göstermekle birlikte, dokunma ihtiyacı ile birlikte bu negatif etkilerde azalma gözlemlenmiştir.
\end{abstract}

Anahtar Kelimeler: Dokunma İhtiyacı, Algılanan Çaba, Algılanan Risk

\begin{abstract}
Touch sense, which is one of the five senses, is used by individuals as a pre-purchase evaluation tool. While the price disadvantage that consumers think they will encounter while purchasing from the store causes them to turn to online shopping, but their need for touch also leads them to shopping from the store. In addition, the effort they will spend to buy from the store also affects their intention to buy from the store. However, since the ease of making price comparisons in the store may affect their perceptions of the risk factor, so that their purchase intentions may also be positively affected. In this study, the subject of examining the need for touch of individuals and in this context, in which direction their shopping tendencies are. Participants were asked to think that they had purchased a new mobile phone, and then research questions were asked. As a result of the research, no difference was observed between men and women in terms of the level of need for touch, but it was observed that as the need for touch increased, so did the behavior of buying from the store. In addition, as the perceived effort and perceived risk increased, the intention to buy from the store decreased, on the other hand, these negative effects decreased with the need for touch.
\end{abstract}

Keywords: Need for touch, Perceived effort, Perceived risk

Balık, Z.S. (2021). "Mağazadan Satın Alma Davranışında Dokunma İhtiyacının Rolü”, Journal of Academic Value Studies 7(2) (2021) 138-145 ().

*E-mail address: zsbalik@sirnak.edu.tr 


\section{Giriş}

OECD'nin 2018 raporuna göre Türkiye'de hane halkı internet erişimi 2005 yılında \%7,7 iken 2018 yılında bu oran \%83,8 olarak belirtilmiştir (OECD, 2018). İnternete erişimin artması ile internet üzerinden alışveriş yapan kişi sayısı da artış göstermektedir (Srinivas, Ramesh ve Sriramoju, 2018, 1692). Günümüzde internet üzerinden mobilya satışı bile gerçekleşmektedir. Üstelik mağaza fiyatının çok daha altında, çeşitli renk ve model bulmak mümkündür. Tüketiciler mağazalardan edinebilecekleri bilgilere internet üzerinden kolaylıkla ulaşabilmekte ve işletmeler de genel olarak pazarlama faaliyetlerini bu platformlardan yürütmektedirler (Yeşilkuş, 2020, 137). Bu durum tüketicilere zaman (mağaza mağaza dolaşmak) ve maliyet avantajı sağlamaktadır (Lynch ve Ariely, 2000, 83). Bununla birlikte, mağazada alışveriş yaptıkları süre içerisinde alacakları ürünlere dokunma ihtiyacı güden ve ürüne ilişkin bilgiyi (kalite, doku, vs.) dokunma duyuları ile elde edebildiklerini düşünen bireyler de bulunmaktadır. (Peck and Childers, 2003, 430). Konu ile ilgilli yapılan araştırmalar da dokunma ihtiyacının internet alışverişlerini etkilediği yönündedir (Gonzalez-Benito, Martos-Partal ve Martin; Lee, Workman ve Jung, 2017).

Araştırmacı, maliyet yönünden belki de daha avantajlı olan internetten alışveriş yapmak dururken, tüketicilerin neden hala mağazadan satın alıma yöneldiklerini, dokunma ihtiyacı değişkeni çerçevesinde incelemeyi amaçlamaktadır. Alan yazında internet alışverişlerini inceleyen pek çok çalışma bulunmakla (Li ve Zhang, 2002; Gefen, Karahanna ve Straub, 2003; Huang, Schrank, Dubinsky, 2004; Rose, Hair ve Clark, 2011; Bleier, Harmeling ve Palmatier, 2018) birlikte, dokunma ihtiyacının online satın alımlara etkisi inceleyen çalışmaların azlığı açısından, literatüre katkı sağlayacağı düşünülmektedir.

Bu amaç doğrultusunda Mersin ilinde ikamet eden kişilerin dokunma ihtiyacı düzeyleri cep telefonu ürün olarak seçilerek araştırma konusu yapılmıştır.

\section{Literatür Analizi}

Geçmişte yapılan araştırmalar, ürünün, durumun ve tüketici özelliklerinin farklı perakende formatlarının sağladığı (örneğin, mağaza, katalog, internet, vb.) göreceli yararları etkilediğini ve bunun doğal bir sonucu olarak tüketicinin alışveriş seçimini etkilediğini belirtmektedirler (Alba, Lynch, Weitz, Janiszewski, Lutz, Sawyer, ve Wood 1997; Citrin, Stem, Spangenberg ve Clark, 2003,915). Tüketicilerin bilgi ararken interneti kullandıkları ve ileride bilgi ararken internete giderek daha fazla güvenecekleri açıktır (Peterson ve Merino, 2003, 104). Internet, minimum çaba ve maliyetle, kişiye sağladığı bilgi miktarı ile karar vermeyi kolaylaştıran ve karar verme sürecini daha verimli hale getiren bilgiler sunmaktadır (Alba vd. 1997; Peterson ve Merino, 2003). İnternet kullanımının oldukça yaygın hale gelmesi ve sanal mağazalarda fiyatların mağaza fiyatlarına göre daha düşük (ucuz) olması internet üzerinden yapılan satışların artmasında bir etken olarak gösterilebilir. İnternetin ticaret için sağlam bir kanal haline gelmesi, hem elektronik pazarların özelliklerini hem de tüketicilerin ticari faaliyetler için interneti kullanmalarını etkileyen faktörleri anlamayı önemli kılmıştır (Citrin vd. 2003,915).

Öte yandan literatür incelemesinde dokunma ihtiyacının internet üzerinden yapılan satın alma davranışını etkilediği görülmüştür (Workman, 2010; Cho ve Workman, 2011). Ürünlere dokunma olanağının, tüketicilerin tutumları ve davranışları üzerinde ikna edici bir etkisi olduğu bilinmektedir (Peck ve Childers, 2003, 430; Peck ve Wiggins,2006,56). Çoğu tüketici, kataloglar, İnternet veya diğer doğrudan araçlarla ürün satın alsa dahi, birçok tüketici bu ortamlarda alım yapmamaktadır. Örneğin, internet üzerinden alışveriş yapmaya yaygın engel olarak, "mallara dokunamama ve fiziksel olarak ürünlerle temas edilememesi" gösterilmektedir (Forrester Research, 1999'den akt. McCabe ve Nowlis, 2003, 431). Bir mağaza ortamında ise, tüketiciler hem dokunma hissine hem de görme duyusuna güvenebilirler ve bu doğrultuda ürün özellikleri mağaza içinde daha doğru incelenebilir (McCabe ve Nowlis, 2003, 432).

Birçok tüketici mağaza içerisindeyken fiyat karşılaştırması yapmak ve ürünler hakkındaki yorumları görmek için araştırma yapabiliyor (Singh ve Swait, 2007, 123). Google’ın yapmış olduğu bir araştırmaya göre, Abd'deki on akıllı telefon kullanıcısından sekizi mağaza içindeyken mobil araştırma yapmaktadır (Kotler, 2017, 46). 2017 yılında özel bir kuruluş tarafından gerçekleştirilen, aralarında Türkiye'nin de olduğu 51 ülkeden, yaşları 15 ile 70 arasında değişen ve son 12 ay içerisinde internetten en az bir ürün satın almış 18 bin 430 tüketicinin katıldığı Küresel İnternet Tüketicileri Araştırması'na göre tüketicilerin \%75’i mağazada bulundukları süre boyunca, 
akıllı telefonlarını kullanarak, aradıkları ürünün diğer kanallardaki fiyatlarını karşılaştırmaktadır (https://home.kpmg/tr, e.t. 05.02.2019).

Canio ve Fuentos-Blasco (2021) Güçlü dokunsal (haptik) özelliklere sahip tüketicilerin fiziksel ve mobil kanalları tercih ettiğini, mobil alışveriş kanallarında da doğrudan dokunma ara yüzüne sahip sitelerin dokunma ihtiyacı yüksek bireyler tarafından tercih edildiğini ifade etmişlerdir. Araştırmaları sonucunda perakendecilerin yüksek dokunsal ürünler için çok kannallı stratejileri uygulamalarının pozitif etki yaratacağını göstermişlerdir (Canio ve Fuentos-Blasco, 2021).

Pino ve arkadaşlarının (2020) elektronik ürünler üzerinden yürüttükleri 3 ayrı çalışma sonucunda bireylerin yalnızca dokunsal fonksiyonel ürünlere dokunmaları ile beklenen kullanım kolaylığını arttırıldığını ve bu etkinin dokunma ihtiyacı yüksek olan tüketiciler arasında gözlemlenebilir olduğuna sonucuna ulaşmışlardır. Ayrıca hayal edilen ürün dokunuşu bile bu ürünlerin beklenen kullanım kolaylığını artırdığını gözlemlemişlerdir (Pino vd, 2020).

İteratürde dokunma ihtiyacını ototelik (kendine özgü amacı olan) ve enstrümantal olarak iki boyutta inceleyen çalışmalar bulunmaktadır (Manzono vd., 2016; Vrana ve Mokry, 2020) Manzono ve arkadaşları (2016) online giysi satın almanın arama ve satın lama aşamalarında tüketici ototelik ve enstrümantal dokunma ihtiyaçlarının etkisini inceleyen araştırmacılar, ototelik ve enstrümantal dokunma ihtiyacı yüksek bireylerin online platformlardan kıyafet satın alma olasılıklarının düşük olduğu sonucuna ulaşmışlardır. Ayrıca faydacı yönelimin enstrümantal dokunma ihtiyacı boyutu ile arama ve satın alma amaçlı online platformların kullanımı arasındaki ilişkiyi ılımlılaştırdığını gözlemlemişlerdir (Manzono vd., 2016 ,5).

\section{Tasarım ve Yöntem}

Mersin ilinde ikamet eden toplamda 400 kişiye anket formu gönderilmiş, 330 anket geri dönmüş, ancak 290 anket analize katılmaya uygun bulunmuştur. Anket uygulaması için farklı ürünler üzerinden sorular yöneltildiğinde, satın alma kararını etkileyen (fiyat, renk, doku vb) unsurlar cevaplayıcıların farklı yanıtlamasına neden olabileceği ön görülerek, tek bir ürün üzerinden katılımcılara anket soruları yöneltilmiştir. Bu amaçla cep telefonu ürün olarak seçilmiş,

\section{"Yeni bir cep telefonu satın almayı planlıyorsunuz. Marka ve modele karar verdiniz. Yakın çevrenizde bu marka ve modeli satın alabileceğiniz mă̆azallar bulunmaktadır"}

ifadesi sunulmuş ve bu ifadeyi dikkate alarak takip eden soruların yanıtlanması istenilmiştir. Katılımcılara "Yakın çevrenizde bu marka ve modeli satın alabileceğiniz mağaza/lar bulunmaktadır" ifadesinin yöneltilmesinin sebebi halihazırda yakın çevrelerinde böyle mağazaların bulunmadığını düşünmelerini engelleyerek, anket ifadelerine daha doğru cevap vermeleri hedeflenmiştir. Çünkü yapılan bazı çalışmalar tüketicinin mağaza uzaklığına göre satın alım kararlarının etkilendiğini göstermektedir (Liberman, Trope, ve Wakslak, 2007; Forman, Ghose, ve Goldfarb, 2009; Chen, Shang, ve Kao, 2009).

Bireylerin dokunma duyusuna ilişkin yapılan çalışmalar, dokunuşun hem insanların ürünü değerlendirmeleri hem de satın alma kararlarında derin bir etkisi olduğunu göstermektedir (Spence ve Gallace, 2011, 292; Soars, 2009, 295). Online alışverişlerde dokunma duyusunun kullanılamaması, online kanallardan satın alımı etkileyen bir unsur olarak karşımıza çıkmaktadır (Flavian, Gurrea ve Orus, 2017, 1548). Peck ve Wiggins (2006) dokunma duyusunun kullanımının online pazarlamanın başlamasıyla birlikte daha çok önem kazandığını belirtmektedirler (Peck ve Wiggins, 2006, 56). Tüketiciler daha önce online alışveriş yaptıkları bir siteye güvendikleri için yeniden online satın alım yapabilmekle birlikte, dokunma olanaklarının olmadığı için çoğunlukla aradıkları ürünü/ürünleri mağazadan satın almayı tercih etmektedirler (Flavian, Gurrea ve Orus, 2017, 1544). Bu bağlamda aşağıdaki hipotezler geliştirilmiştir;

$\mathrm{H}_{1}$ : Dokunma ihtiyacı ile mağazadan satın alma niyeti arasında anlamlı bir ilişki vardır.

Bhatnagar ve Ratchford (2004) bireylerin çok fazla çaba gerektiren durumlarda ya da bütçelerini aşan bir fiyat söz konusu olduğunda mağazaya gitmediklerini belirtmişlerdir (Bhatnagar ve Ratchford, 2004, 42). Bireylerin karar alma süreçlerini kolaylaştırıcı bir etki sağlayan internet (Peterson ve Merino, 2003, 99) kullanımı ve onu takiben İnternet temelli satın alma başta Amerika olmak üzere pek çok ülkede giderek artan bir öneme sahip 
olmaktadır (King, Sen ve Xia, 2004, 103; Beckers, Cardenas ve Verhetsel, 2018, 33). İnternetin karar sürecini kolaylaştırıcı etkisi yanında çok fazla seçeneğe sahip olması dolayısı ile seçim paradoksuna neden olmaktadır. Yapılan çalışmalar çok fazla seçeneğe maruz kalanların daha az seçeneğe sahip olanlar yanında daha fazla zaman ve bilişsel çaba harcadıklarını göstermektedir (Tang, Hsieh ve Chiu, 2017, 19).

vardır

$\mathrm{H}_{2}$ : Algılanan satın alma çabası ile mağazadan satın alma niyeti arasında anlamlı negatif yönde bir ilişki

$\mathrm{H}_{3}$ : Algılanan fiyat riski ile mağazadan satın alma niyeti değişkenleri arasında negatif yönde anlamlı bir ilişki vardır.

$\mathrm{H}_{4}$ : Algılanan arama kolaylığı ile mağazadan satın alma niyeti değişkenleri arasında pozitif yönde doğrusal anlamlı bir ilişki vardır.

Aşağıdaki şekilde öngörülen araştırma modeli verilmiştir (AR-algılanan risk, AÇ- algılanan çaba, AAKalgılanan arama kolaylığı, Dİ-dokunma ihtiyacı, MSN-mağazadan satın alma niyeti);

Şekil 1. Araştırma Modeli

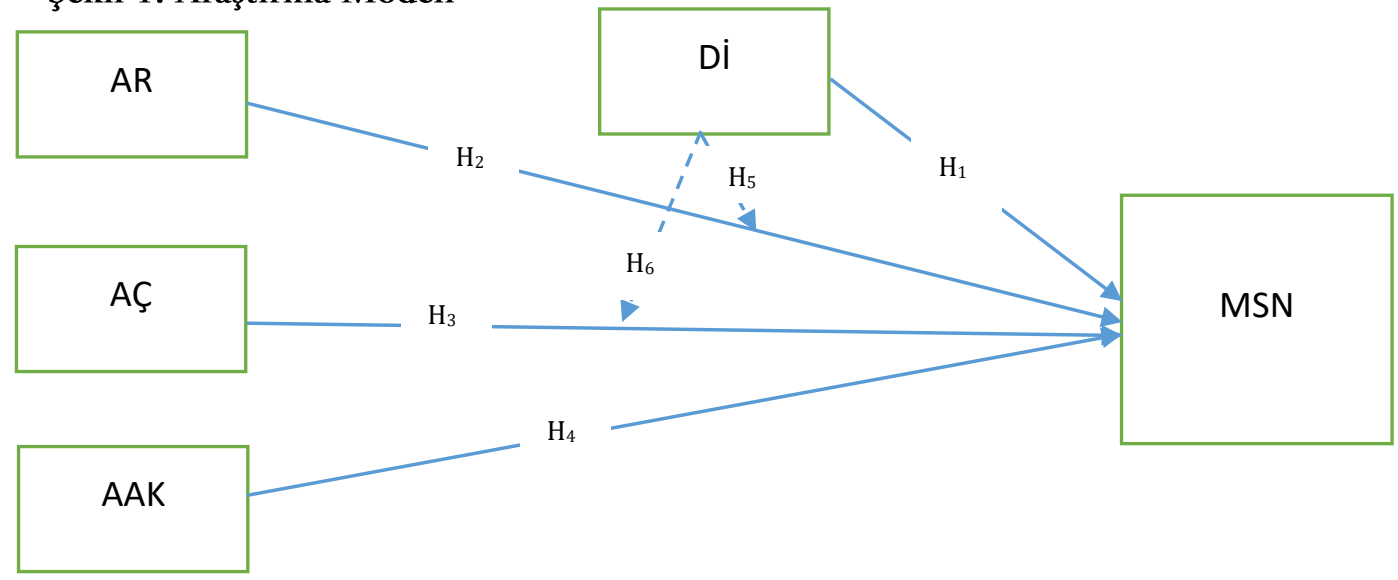

Dokunma ihtiyacının algılan fiyat riski ve algılanan çaba değişkenlerinin mağazadan satın alma niyeti üzerindeki negatif etkisini ılımlaştırıcı bir etkisi söz konusudur.

$\mathrm{H}_{5}$ : Dokunma ihtiyacının algılanan fiyat riski ile mağazadan satın alma davranışı arasındaki ilişkiyi ılımlaştırıcı etkisi vardır.

$\mathrm{H}_{6}$ : Dokunma ihtiyacının algılanan çaba ile mağazadan satın alma davranışı arasındaki ilişkiyi ılımlaştııııı etkisi vardır.

\section{Bulgular ve Tartışma}

Katılımcılara bir ürünü satın almadan önce internet üzerinden fiyat karşılaştırması yapıyor musunuz sorusu yöneltilmiş ve katılımcıların \%73'ü (ayrıca \%17,1 bazen) fiyat karşılaştırması yaptıklarını belirtmişlerdir. Katılımcılara mağazada bulundukları sürede hangi ürünler için fiyat karşılaştırması yaptıkları sorusu yöneltilmiştir. \%7'si hiç fiyat karşılaştırması yapmadıklarını belirtirken, \%93'ü bazı ürünlerde (Teknolojik, elektronik, giyim vb.) fiyat karşılaştırması yapma ihtiyacı hissettiklerini belirtmişlerdir. Bu soruları takiben, doğrudan mağazadan ve doğrudan internetten hangi ürünleri satın aldıkları açık uçlu soru olarak yöneltilmiştir. Doğrudan mağazadan en çok satın aldıkları ürün olarak (\%41) giyim, (\%13) gıda ve (\%13) parfüm olarak belirtmişlerdir. Doğrudan internet üzerinden satın aldıkları ürünler olarak da sırasıyla (\%17) giyim, (\%13) teknolojik ürünler (cep telefonu, bilgisayar vs.), (\%12) elektronik ürünlerdir. Katılımcıların \%11’i hiçbir ürünü internetten satın almadığını belirtmiştir. Katılımcıların \%63’ü mağazadan satın alacaklarını belirtmişlerdir.

Değişkenler güvenilirlik analizine tabi tutulmuş ve aşağıdaki tabloda yer alan sonuçlar elde edilmiştir.

Değişkenler arası ilişkileri belirlemek amacıyla veriler hiyerarşik regresyon analizine tabi tutulmuştur.

Değişkenler arası ilişkilerin incelenmesi amacı ile korelasyon analizi yapılmıştır. Analiz sonuçları tablo 1'de verilmektedir. 
Tablo 1. Değişkenler Arası Korelasyonlar

\begin{tabular}{cccccc}
\hline \hline & MSN & AR & AÇ & AAK & Dí \\
\hline \hline MSN & $\mathbf{1 . 0 0 0}$ & & & & \\
AR & $-.412^{*}$ & $\mathbf{1 . 0 0 0}$ & & & \\
AÇ & $-.343^{*}$ & $.414^{*}$ & $\mathbf{1 . 0 0 0}$ & & \\
AAK & $.278^{*}$ & -.076 & .030 & $\mathbf{1 . 0 0 0}$ & \\
Dí & $.476^{*}$ & $-.343^{*}$ & $-.271^{*}$ & .028 & $\mathbf{1 . 0 0 0}$ \\
\hline \hline
\end{tabular}

${ }^{*} \mathrm{p}<0,001$

Korelasyon analizi sonuçlarına göre tüm değişkenler arasında anlamlı $(\mathrm{p}<0.001)$ bir ilişki mevcuttur. Dokunma ihtiyacı ile algılanan risk $(r=-0.343)$ ve algılanan çaba $(r=-0.343)$ arasında negatif yönlü anlamlı bir ilişkinin olduğu görülmektedir. Dokunma ihtiyacı arttıkça algılanan risk ve algılanan çabanın azalmakta olduğunu söylemek mümkündür ancak bir model olarak etkilerine bakmak için hiyerarşik regresyon analizinden faydalanilacaktır.

Tablo 2. Hiyerarşik Regresyon Analizi Sonuçları

\begin{tabular}{|c|c|c|c|c|c|c|}
\hline & B & t & $F_{\text {değişim }}$ & Df & $\mathbf{R}^{2}$ & $\begin{array}{c}\mathbf{R}^{2} \\
\text { değişimi } \\
\end{array}$ \\
\hline \multicolumn{7}{|l|}{$\begin{array}{l}\text { Bağımlı Değişken } \\
\text { Mağazadan Satın Alma Niyeti } \\
\text { Model 1: }\end{array}$} \\
\hline Algılanan Risk & -.412 & -7.516 & $56.492^{*}$ & 1 & $0.412^{\mathrm{a}}$ & 0.169 \\
\hline \multicolumn{7}{|l|}{ Model 2: } \\
\hline Algılanan Risk & -0.301 & -5.248 & & & & \\
\hline Algılanan Efor & -0.225 & -3.941 & $16.509^{*}$ & 2 & $0.508^{b}$ & 0.089 \\
\hline Algılanan Arama Kolaylığı & 0.232 & 4.438 & & & & \\
\hline \multicolumn{7}{|l|}{ Model 3: } \\
\hline Algılanan Risk & -0.202 & -3.682 & & & & \\
\hline Algilanan Efor & -0.170 & -3.170 & & & & \\
\hline Algılanan Arama Kolaylığı & 0.227 & 4.706 & $46.783^{*}$ & 1 & $0.605^{\mathrm{c}}$ & 0.108 \\
\hline Dokunma İhtiyacı & 0.354 & 6.840 & & & & \\
\hline
\end{tabular}

${ }^{*} \mathrm{p}<0,001$

Tablo 2'ye bakıldığında birinci modelde algılanan risk değişkeni yer alırken ikinci modelde algılanan risk, algılanan çaba ve algılanan arama kolaylığı değişkenleri modele birlikte dahil edilmiştir. Son olarak üçüncü modelde dokunma ihtiyacı değişkeni eklenerek basamaklı analiz gerçekleştirilmiştir. Bütün modeller $\mathrm{p}<0.001$ düzeyinde anlamlı bulunmuştur. İlk modelde algılanan risk mağazadan satın alma niyeti varyansındaki değişimlerin \%41'ini açıklamaktadır. Algılanan risk satın alma niyetini negatif yönde (B: -.412, p<0.001) anlamlı olarak etkilemektedir. Yani algılanan risk arttıkça mağazadan satın alma niyeti düşmektedir. İkinci modelde modele dahil edilen algılanan çaba ve algılanan arama kolaylığı değişkenleri ile mağazadan satın alma niyeti varyansındaki değişimlerin toplamda \%51'i açıklanmaktadır (R2change: .089). 2 ikinci modelde algılanan risk (B: -.301, p<0.001) negatif yönde ancak ilk modele göre azalan bir etkiye, algılanan efor (B: -.225, p<0.001) negatif yönde ve anlamlı bir etkiye ve algılanan 
arama kolaylığı (B: .232, p<0.001) pozitif yönde bir etkiye sahiptir. Modele eklenen algılanan çaba ve algılanan arama kolaylı̆̆ı değişkenlerinin algılanan riskin negatif etkisini ılımlaştırdığını söylemek mümkündür.

Üçüncü modelin mağazadan satın alma davranışı varyansında meydana gelen değişimlerin yaklaşık olarak \%61'ini (R2change: .108) açıkladığı görülmektedir. Dokunma ihtiyacının modele eklenmesi ile açıklanan varyans yüzdesi değişimi \%11 olmuştur. Dokunma ihtiyacının mağazadan satın alma niyeti üzerindeki etkisi ise B: .354 $(\mathrm{p}<0.001)$ düzeyindedir. Son modelde algılanan risk (B: -.202, $\mathrm{p}<0.001)$ negatif yönde ilk iki modele göre azalan bir etkiye, algılanan efor (B: -.170, $\mathrm{p}<0.001)$ negatif yönde ve anlamlı bir etkiye, algılanan arama kolaylı̆̆ı (B: .227, $\mathrm{p}<0.001)$ pozitif yönde bir etkiye sahiptir. Dokunma ihtiyacı İki modelin de mağazadan satın alma davranışının yordanmasında anlamlı ( $\mathrm{p}=0,000)$ katkılarının olduğunu söylemek mümkündür (Alpar, 2018, 455). Dokunma ihtiyacı mağazadan satın alma niyeti ile etkileşimlerinde algılanan risk ve algılanan çabanın negatif etkilerini azaltıcı yani ılımlaştırıcı bir etkiye sahiptir.

Dokunma ihtiyacının cinsiyet değişkeni açısından farklılık gösterip göstermediğini kıyaslamak için bağımsız örneklemler t testi yapılmıştır. Analiz sonuçlarına göre, erkekler $(M=4.07, S D=0.90)$ ve kadınlardan $(\mathrm{M}=3.95, \mathrm{SD}=0.74 ; \mathrm{t}(290)=1.30, \mathrm{p}=.20)$ elde edilen puanlar arasında anlamlı bir fark gözlemlenmemiştir. Bu sonuçlara göre, kadınlar ve erkekler için dokunma ihtiyacı açısından anlamlı bir farklılık olmadığını söylemek mümkündür. Algılanan satın alma çabasının cinsiyet açısından farklılık gösterip göstermediğini kıyaslama açııından da bağımsız örneklem t testi yapılmışıır. Elde edilen sonuçlara göre kadın ve erkekler arasında algılanan satın alma çabasında anlamlı bir farklılık ( $\mathrm{p}=0.51$ ) olmadığı görülmüştür (Mkadın=2.90 SD=0.99; Merkek=2.77, $\mathrm{SD}=0.95)$.

\section{Sonuç, Öneriler ve Kısıtlar}

Yapılan araştırma sonucunda katılımcıların \%90'ının mağazada bulundukları sürede fiyat karşılaştırması yapma ihtiyacı duydukları gözlemlenmiştir. Araştırmalar İnternet temelli tüketimin giderek arttığını (King, Sen ve Xia, 2004, 103; Beckers, Cardenas ve Verhetsel, 2018, 33) ve tüketiciler internetin fiyat karşılaştırması ve farklı ürün seçenekleri sunması gibi avantajları sunduğunu (Peterson ve Merino, 2003, 99) göstermektedir. Bununla birlikte yüksek fiyat riski olduğu için tüketiciler mağazaya yönelmemeyi tercih edebilmektedirler (Bhatnagar ve Ratchford, 2004, 42). Çalışma sonucunda algılanan fiyat riski ve algılanan çaba mağazadan satın alma davranışını olumsuz etkilerken, dokunma ihtiyacı değişkeni bu etkileri ılımlaştırıcı bir etkiye sahip olmanın yanında mağazadan satın alma niyetini olumlu yönde etkileyen bir etkiye sahip olduğu gözlemlenmiştir. Daha açık bir ifadeyle, bireyler gelişen teknolojiye, bilgi arama (fiyat karşılaştırması yapma gibi) amacıyla kullanma yönünde adaptasyon sağlarken, yüksek dokunma ihtiyacının bir sonucu olarak internet üzerinden daha uygun bir fiyata ürün bulsalar dahi, mağazadan satın almayı tercih etmektedirler. Mağaza içerisindeyken tüketicilerin internetten fiyat karşılaştırması yapabilme kolaylığı da (algılanan arama kolaylığı değişkeni ile ölçülmüştür) mağazadan satın alma niyetini olumlu yönde etkilemektedir.

Araştırma sonuçlarında dokunma ihtiyacı değişkeni için cinsiyet açısından bir farklılık gözlemlenmemiştir. Firmaların hedef kitleleri kadın ya da erkek olması fark etmeksizin tutundurma çabalarında dokunma ihtiyacını göz önünde bulundurmaları gerektiğini söylemek mümkündür.

Araştırma Mersin ilinde ikamet eden kişiler arasında, çoğunlukla üniversite öğrencilerinden oluşan bir örneklem ile gerçekleştirilmiştir. Bu durum çalışmanın kısıtlarından birini oluşturmaktadır. Bununla birlikte, araştırmanın cep telefonu gibi sık satın alınmayan ve görece pahalı bir ürün örneği üzerinden gerçekleştirilmesi, tüketiciler açısından daha fazla maliyete neden olması yönünden, satın alım tercihlerini etkilemesi olası olduğundan, diğer bir kısıtı oluşturmaktadır. Katılımcılara doğrudan internet üzerinden (mağazada görmeye ihtiyaç duymaksızın) satın aldıkları ürün sorulmuş ve en çok giyim ürünleri aldıkları sonucuna ulaşılmıştır. Gelecek çalışmalar giyim ürünleri üzerinden araştırmalarını genişletmenin yanı sıra neden giyim ürünleri olduğunu da ayrıca araştırma konusu yapılabilir.

Araştırma verileri pandemi öncesinde toplanmış verilerdir. Pandemi sonrasında yeniden dokunma ihtiyacı konusunda bir çalışmanın yapılması salgın hastalık dönemlerinde bu ihtiyacın mağazadan satın alma niyeti üzerinde nasıl bir etkisi olduğunu tespit etme olanağı sağlayacaktır. Bununla birlikte online alısverişe ilişkin risk azaltan unsurların (koşulsuz iade garantisi, uzun deneme süreci, numune gönderimi vs.) bulunduğu durumda 
mağazadan veya elektronik ortamda satın alıma ne gibi etkisinin olacağı ve bu etkileşimde dokunma ihtiyacının rolüne ilişkin çalışmalar yapılması literatüre önemli ölçüde katkı sağlayacaktır.

\section{Kaynakça}

Alba, J., Lynch, J., Weitz, B., Janiszewski, C., Lutz, R., Sawyer, A., \& Wood, S. (1997). Interactive home shopping: consumer, retailer, and manufacturer incentives to participate in electronic marketplaces. The Journal of Marketing, 38-53.

Alpar, R. (2018). Uygulamalı istatistik ve geçerlik-güvenirlik: spor, sağlık ve eğitim bilimlerinden örneklerle. 5. Baskı, Detay Yayıncılık, Ankara.

Beckers, J., Cárdenas, I., \& Verhetsel, A. (2018). Identifying the geography of online shopping adoption in Belgium. Journal of Retailing and Consumer Services, 45, 33-41.

Bhatnagar, A., \& Ratchford, B. T. (2004). A model of retail format competition for non-durable goods. International Journal of Research in Marketing, 21(1), 39-59.

Bleier, A., Harmeling, C. M., \& Palmatier, R. W. (2018). Creating Effective Online Customer Experiences. Journal of Marketing, 0022242918809930.

Chen, Y. C., Shang, R. A., \& Kao, C. Y. (2009). The effects of information overload on consumers' subjective state towards buying decision in the internet shopping environment. Electronic Commerce Research and Applications, 8(1), 48-58.

Cho, S., \& Workman, J. (2011). Gender, fashion innovativeness and opinion leadership, and need for touch: Effects on multi-channel choice and touch/non-touch preference in clothing shopping. Journal of Fashion Marketing and Management: An International Journal, 15(3), 363-382.

Citrin, A. V., Stem Jr, D. E., Spangenberg, E. R., \& Clark, M. J. (2003). Consumer need for tactile input: An internet retailing challenge. Journal of Business Research, 56(11), 915-922.

De Canio, F., \& Fuentes-Blasco, M. (2021). I need to touch it to buy it! How haptic information influences consumer shopping behavior across channels. Journal of Retailing and Consumer Services, 61, 102569.

Flavián, C., Gurrea, R., \& Orús, C. (2017). The influence of online product presentation videos on persuasion and purchase channel preference: The role of imagery fluency and need for touch. Telematics and Informatics, 34(8), 1544-1556.

Forman, C., Ghose, A., \& Goldfarb, A. (2009). Competition between local and electronic markets: How the benefit of buying online depends on where you live. Management Science, 55(1), 47-57.

Gefen, D., Karahanna, E., \& Straub, D. W. (2003). Trust and TAM in online shopping: an integrated model. MIS Quarterly, 27(1), 51-90.

González-Benito, Ó., Martos-Partal, M., \& San Martín, S. (2015). Brands as substitutes for the need for touch in online shopping. Journal of Retailing and Consumer Services, 27, 121-125.

Huang, W. Y., Schrank, H., \& Dubinsky, A. J. (2004). Effect of brand name on consumers' risk perceptions of online shopping. Journal of Consumer Behaviour: An International Research Review, 4(1), 40-50.

King, R. C., Sen, R., \& Xia, M. (2004). Impact of web-based e-commerce on channel strategy in retailing. International Journal of Electronic Commerce, 8(3), 103-130.

Kotler, F. (2017). Pazarlama 4.0: Gelenekselden Dijitale Geçiş. Özata N.(Çev.) İstanbul: Optimist Yayınları.

Lee, S. H., Workman, J. E., \& Jung, K. (2017). The influence of need for touch and gender on Internet shopping attitudes among Korean consumers. International Journal of Fashion Design, Technology and Education, 10(2), 230-239.

Li, N., \& Zhang, P. (2002). Consumer online shopping attitudes and behavior: An assessment of research. AMCIS 2002 Proceedings, 74. 
Liberman, N., Trope, Y., \& Wakslak, C. (2007). Construal level theory and consumer behavior. Journal of Consumer Psychology, 17(2), 113-117.

Lynch Jr, J. G., \& Ariely, D. (2000). Wine online: Search costs affect competition on price, quality, and distribution. Marketing Science, 19(1), 83-103.

Manzano, R., Gavilan, D., Ferran, M., Avello, M., \& Abril, C. (2016). Autotelic and instrumental need for touch: Searching for and purchasing apparel online. International Journal of Economics \& Management Sciences, 5(2):322.

McCabe, D. B., \& Nowlis, S. M. (2003). The effect of examining actual products or product descriptions on consumer preference. Journal of Consumer Psychology, 13(4), 431-439.

Peck, J., \& Childers, T. L. (2003). Individual differences in haptic information processing: The "need for touch" scale. Journal of Consumer Research, 30(3), 430-442.

Peck, J., \& Wiggins, J. (2006). It just feels good: Customers' affective response to touch and its influence on persuasion. Journal of Marketing, 70(4), 56-69.

Peterson, R. A., \& Merino, M. C. (2003). Consumer information search behavior and the Internet. Psychology \& Marketing, 20(2), 99-121.

Pino, G., Amatulli, C., Nataraajan, R., De Angelis, M., Peluso, A. M., \& Guido, G. (2020). Product touch in the real and digital world: How do consumers react?. Journal of Business Research, 112, 492-501.

Rose, S., Hair, N., \& Clark, M. (2011). Online customer experience: A review of the business-to-consumer online purchase context. International Journal of Management Reviews, 13(1), 24-39.

Singh, S., \& Swait, J. (2017). Channels for search and purchase: Does mobile Internet matter?. Journal of Retailing and Consumer Services, 39, 123-134.

Soars, B. (2009). Driving sales through shoppers' sense of sound, sight, smell and touch. International Journal of Retail \& Distribution Management, 37(3), 286-298.

Spence, C., \& Gallace, A. (2011). Multisensory design: Reaching out to touch the consumer. Psychology \& Marketing, 28(3), 267-308.

Srinivas, B., Ramesh, G., \& Sriramoju, S. B. (2018). An Overview of Classification Rule and Association Rule Mining. International Journal of Scientific Research in Computer Science, Engineering and Information Technology, 3(1), 643-650.

Tang, Y. C., Hsieh, Y. C., \& Chiu, H. C. (2017). Purchase decision: does too much choice leave us unhappy?. European Journal of Marketing, 51(7/8), 1248-1265.

Vrána, J., \& Mokrý, S. (2020, November). The "Need For Touch" And Czech Generation Y. In European Scientific Conference of Doctoral Students (p. 211).

Workman, J. E. (2010). Fashion consumer groups, gender, and need for touch. Clothing and Textiles Research Journal, 28(2), 126-139.

Yeşilkuş, F. (2020). Tüketici Karar Verme Tarzlarının E-Müşteri Algıları Üzerindeki Etkisi. Journal of Academic Value Studies, 6(2), 136-151.

Elektronik Kaynaklar

https://data.oecd.org/ict/internet-access.html, e.t. 04.02.2019

https:/home.kpmg/tr/tr/home/gorusler/2017/07/2017-kuresel-internet-tuketicileri-arastirmasi.html, e.t. 05.02.2019 